\section{Visión Electrónica \\ Más que un estado sólido}

http: revistas.udistrital.edu.co/ojs/index.php/visele/index

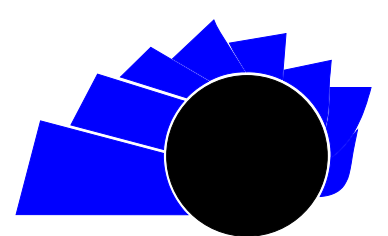

VISIÓN ELECTRÓNICA
UNIVERSIDAD DISTRITAL FRANCISCO JOSÉ DE CALDAS

A CONTEXT VISION

\title{
Analytical foundation of the planimeter
}

\author{
Fundamento analítico del planímetro
}

Claudia Vela Urrego. ${ }^{1}$, Edilberto Sarmiento Sarmiento. ${ }^{2}$, Edier Hernan Bustos Velazco..$^{3}$

INFORMACIÓN DEL ARTÍCULO

\section{Historia del artículo:}

Enviado: 03/08/2017

Recibido: $12 / 09 / 2017$

Aceptado: 23/11/2017

\section{Keywords:}

Analityc foundation

Planimeter

Topographic engineering.

\begin{abstract}
One of the main objectives of topographic surveys has allowed to draw maps or plans of an area of a limited region or terrain, showing physical characteristics of the terrain, such as rivers, lakes, reservoirs, roads, forests, rock formations, ponds, dams, dikes, drainage pits or water supply channels. The accuracy of the measurement will depend on the scale of the map, the method and the instruments utilized. This document provides the mathematical fundamentals of the planimeter, that allows to measure the area of uneven or spherical flat surfaces; this instrument is important in topographic engineering. The knowledge, and the analityc foundation, of this instrument, makes the article not only of a pedagogical nature, but also it provides a historical development depicting its evolution and leading to its digital current version.
\end{abstract}

\section{Open access}

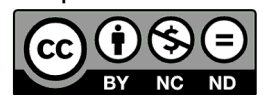

Palabras clave:

Fundamentos analíticos Planímetro Ingeniería topográfica.

\section{RESUMEN}

Uno de los objetivos principales de los levantamientos topográficos permite dibujar mapas o planos de un área de una región o terreno limitado, que muestra las características físicas del mismo: ríos, lagos, embalses, caminos, bosques, formaciones rocosas, estanques, represas, diques, pozos de drenaje o canales de suministro de agua. La precisión de la medición dependerá de la escala del mapa, el método y el instrumento utilizado. El presente documento proporciona los fundamentos matemáticos del planímetro, instrumento que permite medir el área de superficies planas irregulares o esféricas, y el cual es importante en la ingeniería topográfica. El conocimiento y la base analítica de este instrumento hacen que el artículo no solo sea de naturaleza pedagógica, sino que también proporciona un desarrollo histórico que describe su evolución y conduce a la justificación de su versión digital actual.

\footnotetext{
${ }^{1}$ BSc. In Mathematical education, Universidad Distrital Francisco José de Caldas, Colombia. Phd. In Matehmatical education. Current position: Professor, Universidad Distrital Francisco José de Caldas, Colombia. E-mail: cvela@udistrital.edu.co.

2 BSc. Mathematical education, Universidad Distrital Francisco José de Caldas, Colombia. Msc. In Mathematics, Universidad Nacional de Colombia, Colombia. Current position: Professor Universidad Distrital Francisco José de Caldas, Colombia and SCIBAS investigation group researcher. E-mail: esarmientos@udistrital.edu.co.

${ }^{3}$ MSc. docencia de las matemáticas, Universidad pedagógica Nacional, PhD. en educación, énfasis enseñanza de las ciencias, Universidad Distrital Francisco José de Caldas, PhD (c) en Geografía, Universidad Nacional de la Plata, Argentina. Currente position: Professor Universidad Distrital Francisco José de Caldas. E-mail: ehbustosv@udistrital.edu.co.
} 


\section{Introduction}

At the beginning of the nineteenth century, in the midst of the industrial revolution, there was a need for an instrument that measured areas of land and buildings more accurately, represented on a flat surface. That instrument was called a "planimeter" . Initially, they were designed by engineers who developed several devices. Later, other prototypes were constructed with variations that improved the precision of these instruments.

Different models of planimeters were elaborated and a number of modifications were made from these designs. The best planimeters are the linear, the polar and the radial plan. The first planimeter (Figure 1) was designed by the engineer Johann M. Hermann [1] in 1814, a kind of cone rotating on an axis, which is compatible with a wheel that spins with it. It was a very basic planimeter, being a direct application of the definite integral $\int(y) d x$. In 1816, Lammle improved this version of the device, which was constructed in 1817 . The engineer Johannes Oppikofer invented another planimeter in 1826, which was constructed in 1834, in Paris. Early in 1849, Kaspar Wetli [2-5] invented another one that was built by Georg Christoph Starke.

Figure 1: Hermann Planimeter [1].

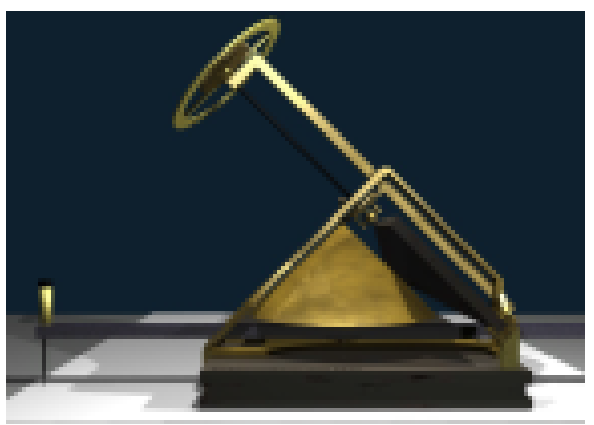

An important change was made in the planimeter, in relation to its design and concept, it was performed by the Swiss mathematician Jakob Amsler-Laffon [6], which was constructed in 1854, based on the polar and linear designs (Figure 2). The modern polar planimeter consists on two articulated arms, for they move along a circle at the point where they are coupled. In a linear planimeter, this last point moves along a straight slot. He also designed a spherical model in 1884. Even though he did not industrialize it, his prototype was constructed and it is in exposition in the Arts and Crafts Museum, in Paris. A radial planimeter was also designed, which measures the average radius of a polar graphic and serves as a polar or linear planimeter.

Figure 2: Polar and linear Planimeters [2].

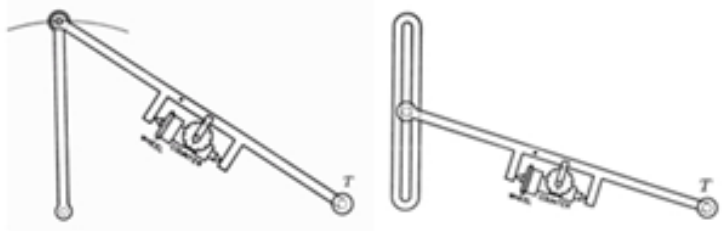

However, an atypical planimeter was designed by the mathematician and Danish Official Holger Prytz [2] in 1875, and it was made in Denmark since 1887. It has a simple design (Figure 3), and the accuracy of its measurements is limited. It was a simple and economical alternative to the costly Amsler's polar design, and it was also easy to transport.

Figure 3: Pritz Planimeter [2].

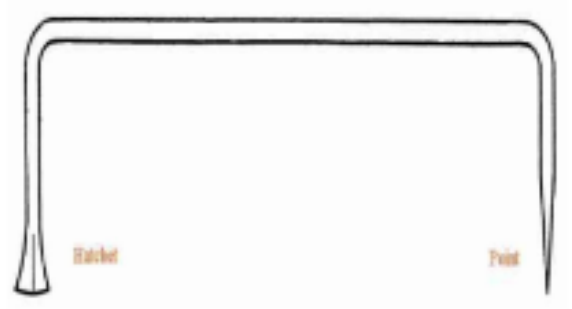

At present, the planimeters are still in use, but they are now digital or with a needle. The procedure remains the same, since it still utilizes the analogical planimeter techniques, the difference being that it is easy to handle, for it does not need to compare with previous readings to make the differentiation, because the data is entered directly, being fed to a computer program, which performs the operations using a software.

\section{The planimeter}

As explained above, the planimeter is an instrument that was created to find areas of irregular figures on scaled planes. As it goes deeper into it, it is seen the innumerable modifications, but all are based on basic theories, such as:

- Cartesian

- Linear 
- Curvilinear

- Polar

It is explained these models as follows.

\subsection{The Cartesian Planimeter}

It represents a point in a plane, in a two-dimensional space, where a reference system is established that places us in relation to a common origin.

Among the many Cartesian planimeters designed at the turn of the nineteenth century, the design made by Jose Ruiz-Castizo [7-10], one of the few that was designed in Spain and constructed by a Swiss company. The author explained its mechanical functions and its analytical justification in the magazine Revista de Obras Publicas de España [7].

Ruiz-Castizo considered, as observed in figure 4, the description of the instrument that starts with the curve $y=f(x)$, where the point MP of the triangle rectangle MQP and the longitude unites the points $\mathrm{M}$ and $\mathrm{P}$, forming the hypotenuse, the cathetus $\mathrm{PQ}$ is constant, the second cathetus QM is the one that constantly changes position, magnitude and direction, it takes the new variable direction as the guideline of the tangent to a new curve $Y=F(x)$, a point $\mathrm{N}$, arbitrary, the ordinate $\mathrm{MP}$, and when it moves again the MQ line, it generates a parallel NN' to the new cathetus M'Q', and so on, and while constantly changing it generates a system of lines that forms a family of straight lines, which is given by the new function $Y=F(x)$, which is a family of straight lines, forming an enveloping.

Figure 4: Generation of the enveloping [10].

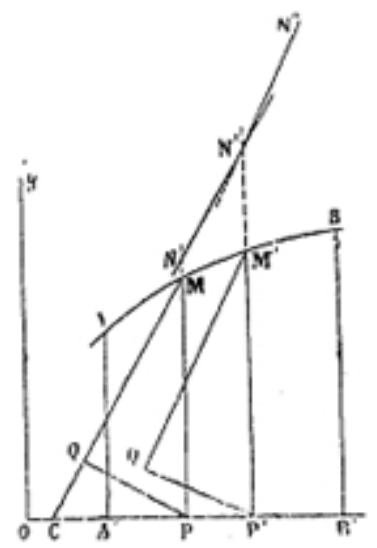

The relationship between the two curves is given by the difference of the triangles MCP and MPQ, where the differential is:

$$
\frac{d Y}{d x}=\tan (M C P)=\tan (M P Q)=\frac{M P}{M Q}
$$

with which the arc of the curve is described with the expression:

$$
d \sigma=\sqrt{1+\frac{y^{2}-a^{2}}{a^{2}}}=\frac{y}{a}=y d y
$$

and when it is integrated, it obtains:

$$
a\left(\sigma_{1}-\sigma_{0}\right)=\int_{x_{0}}^{x_{1}} y d x
$$

The planimeter, Figure 5 , is in accordance with the geometric construction and its analytical justification, the device has two rules, XX', YY', plus one piece YD" with a straight angle at D. The ruele YY' moves perpendicularly to XX', which is fixed, at the end of the movements in the piece XX', at the same time as Y Y', and the piece has a movement within the device "M. ${ }^{a} \mathrm{~S}$ it moves along $\mathrm{Y} \mathrm{Y}^{\prime}$, this device $\mathrm{M}$ carries a pointer that moves along the given curve. Another device $\mathrm{R}$ moves between $\mathrm{YY}^{\prime}$ connected to $\mathrm{M}$ by a mechanism that forces $\mathrm{R}$ to move in the direction of $\mathrm{DD}$ ', which describes the envelope by a wheel, whose rotation is recorded to measure its length, equal to the surface of the given curve. This is a mechanism that performs the movement of Y DD ', when the pointer is in M, it moves along the given curve, to the device $\mathrm{R}$ in which the wheel moves without falling down, with an appropriate inclination, as in its first sketches.

Figure 5: Initial sketch [10].

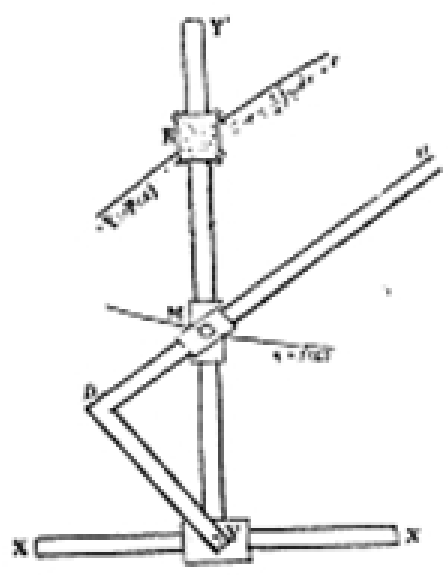

The planimeter works for open, closed convex and closed non-convex curves. The displacement of the base of $\mathrm{NN}^{\prime}$ ' has as an expression $d s=\mid d x$, then give the arc of the curve a $\sigma$, which measures the quotient of an area by the base, and describes three types of curves. 
- The first is an open curve, with its respective limits $\left(x_{0}, x_{1}\right)$ and $\left(\sigma_{0}, \sigma_{1}\right)$, resulting in the expression (3):

$$
\left(\sigma_{1}-\sigma_{0}\right)=\frac{1}{a} \int_{x_{0}}^{x_{1}} y d s+c
$$

which is the general concept, that is a concluded from.

- For a closed convex curve, the movement happens in two times, from AB and from BC. Ruiz-Castizo developed it in the following manner:

$$
\begin{aligned}
\left(\sigma_{1}-\sigma_{0}\right)+\left(\sigma_{o}^{\prime}-\sigma_{0}\right) & =\frac{1}{a} \int_{x_{0}}^{x_{1}} y d x+\frac{-1}{a} \int_{x_{0}}^{x_{1}} y^{\prime} d x \\
& =\frac{1}{a} \int_{x_{0}}^{x_{1}}\left(y-y^{\prime}\right) d x
\end{aligned}
$$

\subsubsection{The Rolling Planimeter}

The rolling planimeter, as seen in Figure 7 below, consists of a pivot, a roller, a wheel, the arm of the tracer and the tracer ${ }^{5}$.

Figure 7: Rolling Planimeter [4].

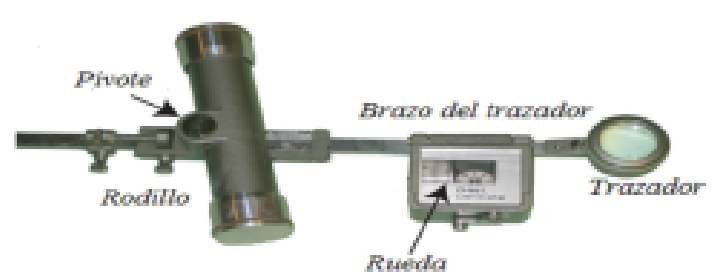

Let $P=(x, y)$ being a point on the closed smooth curve $\mathrm{C}$ boundary of a simply connected region $\mathrm{R}$, and let us suppose that $(0, Y)$ describes the pivot position of the rolling planimeter as shown in Figure 8. The planimeter's movements goes only forwards and backwards, now considering the pivot moving up and down on the $\mathrm{Y}$ axis and linked to a line segment of fixed length $L$ towards the tracer in $P=(x ; y) \in C$. as the planimeter traces the curve, the pivot moves up and down the y axis while the tracer arm rotates over the pivot.

Considering that the tracer is moving along a portion of a very small curve of $C$, from a point $(x, y)$ counterclockwise until $(x+d x, y+d y)$. The pivot has a corresponding shift from the position $(0 ; Y)$ to $(0, Y+$ $d Y$ ). It is desired to determine the measure (in turns) of the wheel on the arm of the tracer resulting from this small movement, which can be decomposed into two parts. First, the pivot is turned along the $Y$ axis of $(0, Y)$ to $(0, Y+d Y)$, so the arm of the tracer maintain a fixed angle of $\alpha$ between the $Y$ axis and the segment that unites the pivot and the tracer.

Figure 8: Rolling Planimeter.

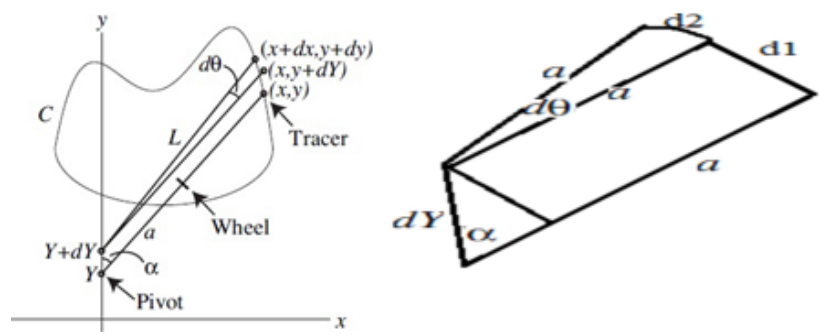

Source: own

\subsubsection{The Rolling and Polar Planimeter}

The structure of these two models are very similar and they are a clear example where the theory of vector calculus is applied, since it is avoided to work with complex trigonometric and algebraic integrals, which is simplified by applying Green's theorem ${ }^{4}$.

\footnotetext{
${ }^{4}$ Green's theorem is called this way after the British scientist George Green. This theorem relates a line integral around a closed and simple curve C, a double integral over the flat region D limited by C, being a special case of Stokes' Theorem

${ }^{5}$ for further information see Tanya Leise [4]
} 
Then, the tracer rotates in an angle $d \theta$ (without moving the roll) so the tracer moves from $(x, y+d Y)$ to $(x+d x, y+d y)$. Nevertheless, during this operation the wheel on the tracer arm rolls a distance without $\alpha d Y+a d \theta=x / L d Y+a d \theta$, since only the component of the movement perpendicular to the tracer arm affects the movement of the wheel. The planimeter returns to its original position after traveling all $C$ and so the angle of rotation of the tracer arm is again $0, \int_{C} d \theta=0$, therefore the total distance traveled by the wheel of the tracer arm is:

$$
D T R=\frac{1}{L} \int_{C} x d Y
$$

It can be seen that $x^{2}+(y-Y)^{2}=L^{2}$, since the tracer arm can not rotate (passing the roller) we have just one value of $Y$ for each point $(x, y)$ which is $Y=y-\sqrt{L 2-x^{2}}$ (given the orientation of the planimeter as shown in Figure 8, the tracer is always above the pivot, which is $Y<y$ ). This implies that $d Y=d y+\frac{x}{L^{2}-x^{2}} d x$. When applying Green's Theorem ${ }^{6}$. We see that $\int_{C} \frac{x}{L^{2}-x^{2}} d x=0$ and we discover that the total distance traveled is

$$
D T R=\frac{1}{L} \int_{C}\left(x d y+\frac{x^{2}}{L^{2}-x^{2}} d x\right)=\frac{1}{L} \int_{C} x d Y
$$

Therefore, the area enclosed by curve $C$ is equal to the length $L$ of the tracer arm by the total distance traveled by the wheel.

\subsubsection{The Polar Planimeter}

A planimeter as the one in Figure 9 consists of a pole, a polar arm, a pivot, a wheel, a tracer arm and a tracer.

It can be verified the polar planimeter, replacing the point $(0, Y)$ with $(b \cos \phi ; b \sin \phi)$ to mirror the circular motion of the pivot; consider the motion of the tracer of the polar planimeter moving along a small portion of the $\mathrm{C}$ curve from the point $(x, y)$ to the point $(x+d x, y+$ $d y)$. The pivot has a correspondent displacement from the position $(b \cos \phi ; b \sin \phi)$ to the position $(b \cos (\phi+$ $d \phi), b \sin (\phi+d \phi))$. Since a displacement is considered infinitesimal, It can linearize the new coordinates, which are converted in (8):

$$
(b \cos \phi-b \sin \phi d \phi, b \sin \phi+b \cos \phi d \phi)
$$

Figure 9: Polar Planimeter [4].

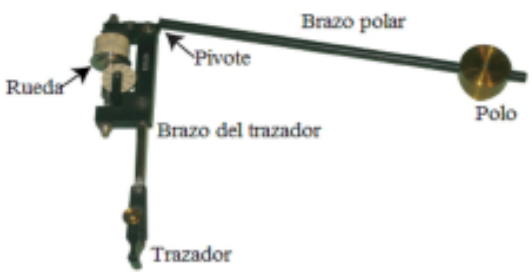

Additionally, the movement is broken down into two parts. First, the pivot rolls along the arc to its new position with the tracer arm parallel to its original orientation, then the tracer moves to $(x-b \sin \phi d \phi y+$ $b \cos \phi d \phi)$ as shown in figure 10. During this operation, only the component of the movement perpendicular to the tracer arm affects the movement of the wheel and the wheel rotates a distance equal to the point product of the displacement vector with the unit vector perpendicular to the tracer arm, then the tracer arm rotates an $d \theta$ (without changing the pivot position). So the tracer reaches the final point $(x+d x ; y+d y)$ and the wheel rolls a distance $a d \theta$. The wheel covers a combined distance during these two small movements of (10):

$$
\begin{array}{r}
\frac{1}{L}(b \sin \phi-y, x-b \cos \phi) \cdot(-b \sin \phi, b \cos \phi) d \phi+a d \theta= \\
\frac{b}{L}(x \cos \phi+y \sin \phi-b) d \phi+a d \theta
\end{array}
$$

The planimeter returns to its original position after travelling along the entire $\mathrm{C}$ curve, so that the total angle $\int_{C} d \theta$ of the tracer arm rotation is equal to a 0 , just like the total angle $\int_{C} d \theta$ of rotation of the polar arm. Therefore, the total distance travelled by the wheel of the tracer arm is:

$$
D T R=\frac{b}{L} \int_{C}(x \cos \phi+y \sin \phi) d \phi
$$

Note that:

$$
(x-b \cos \phi)^{2}+(y-b \sin \phi)^{2}=L^{2}
$$

and, when we transform the polar coordinates $x=$ $r \cos \phi, y=r \sin \phi$, we obtain:

$$
(r \cos \theta-b \cos \phi)^{2}+(r \sin \theta-b \sin \phi)^{2}=L^{2}
$$

When operating it, we obtain:

\footnotetext{
${ }^{6}$ For the theorem on Green's theorem, see texts $[8,9]$ and $[3]$
} 
Figure 10: Polar Planimeter.

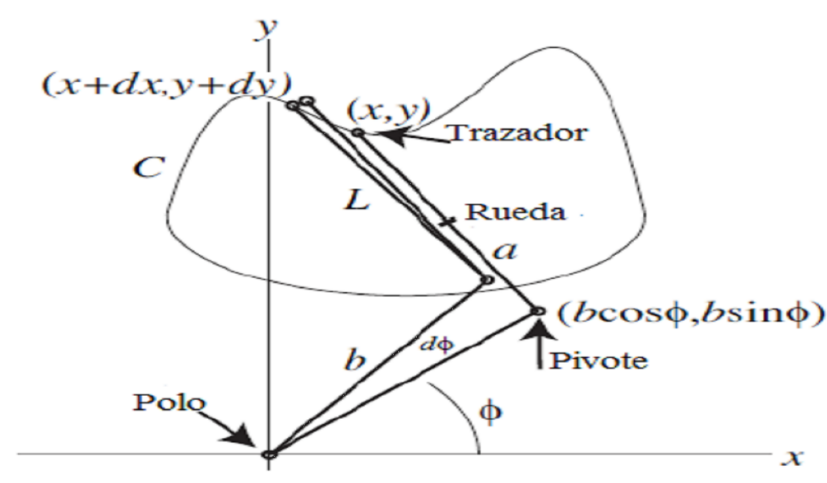

Source: own

$$
\begin{aligned}
& r^{2} \cos ^{2} \theta-2 r b \cos \theta \cos \phi+b^{2} \cos ^{2} \phi+ \\
& r^{2} \sin ^{2} \theta-2 r b \sin \theta \sin \phi+b^{2} \sin ^{2} \phi=L^{2} \\
& r^{2}-2 r b(\cos \theta \cos \phi+\sin \theta \sin \phi)+b^{2}=L^{2}
\end{aligned}
$$

Working the trigonometric identity: $\cos (\theta-\phi)=$ $\frac{r^{2}+b^{2}-L^{2}}{2 r b}$, liberating

$$
\phi=\theta-\cos ^{-1}\left(\frac{r^{2}+b^{2}-L^{2}}{2 r b}\right)
$$

and deriving,

$$
d \phi=d \theta-\frac{-1}{\sqrt{1-\left(\frac{r^{2}+b^{2}-L^{2}}{2 r b}\right)^{2}}} \frac{4 r^{2} b-\left(r^{2}+b^{2}-L^{2}\right) 2 b}{(2 r b)^{2}}
$$

$$
d \phi=d \theta+\frac{r^{2}-b^{2}+L^{2}}{r \sqrt{4 r^{2} b^{2}-\left(r^{2}+b^{2}-L^{2}\right)^{2}}} d r
$$

This way the integral $D T R=\frac{b}{L} \int_{C}(x \cos \phi+$ $y \sin \phi) d \phi$ in polar coordinates is transformed in

$$
\begin{gathered}
D T R=\frac{b}{L} \int_{C}(x \cos \phi+y \sin \phi) d \phi= \\
\frac{b}{L}((r \cos \theta \cos \phi+r \sin \theta \sin \phi) d \phi)
\end{gathered}
$$

where $C^{\prime}$ is the curve in the level $r \theta$ correspondent to $C$ in the level $x y$

$$
=\frac{b}{L} \int_{C^{\prime}} r \cos (\theta-\phi) d \phi
$$

$\frac{b}{L} \int_{C^{\prime}}\left(\frac{r^{2}+b^{2}-L^{2}}{2 b}\left(d \theta+\frac{r^{2}-b^{2}+L^{2}}{r \sqrt{4 r^{2} b^{2}-\left(r^{2}+b^{2}-L^{2}\right)}}\right)\right) d \phi$

$$
\begin{gathered}
=\frac{b}{L} \int_{R} \frac{\partial}{\partial r}\left(\frac{r^{2}+b^{2}-L^{2}}{2 b}\right) d r d \theta, \text { by the grenn Theorem } \\
=\frac{1}{L} \iint_{R} d d r d \theta \\
=\frac{1}{L}(\text { area de } R)
\end{gathered}
$$

Therefore, the area of region $\mathrm{R}$ enclosed by $C$ is $L$ times the total distance traveled by the wheel of the tracer arm and this equality mathematically shows the operation of the polar planimeter.

\section{Conclusions}

We have presented part of the historical development of the Planimeter, a measurement instrument used in cartography and topography these areas are of knowledge transverse to the earth sciences, as well as the evolution of the Cartesian planimeter, the rolling planimeter and the polar planimeter. After this, we presented deductions that allowed us to represent it by using mathematics, initially utilizing the concept of the definite integral and then with the application of Green's theorem as a language for the modeling of its functioning, thus demonstrating the effectiveness of the instrument and its accuracy in the measurement of areas on different regions.

\section{References}

[1] C. Florián, "A history of mathematics", Chelsea Publishing, 1985.

[2] A. Krahe, "El planímetro de Prytz", may 12 th 2017. [Online] Available: http://ropdigital.ciccp.es/ pdf/publico/1925/1925_tomoI_2429_02.pdf

[3] J. E. Marsden, A. J. Tromba "Cálculo vectorial", 5a. edición, Wilmington, Addison-Wesley Iberoamericana, 2004.

[4] T. Leise, "As the Planimeters Wheel Turns: Planimeter Proofs for Calculus Class", may 12 th 2017. [Online] Available: https://tleise.people. amherst. edu/HomePage/LeisePlanimeter.pdf

[5] L. Rute, "Planímetro de Wetli y Starke", ROP, 1867, pp. 269-271.

[6] L. Rute, "Planímetro de Amsler y Polar", ROP, 1870, pp. 269-271.

[7] J. Ruiz "Un nuevo planímetro", Revista de Obras Publicas, vol 44, no. 1149, 1896, pp. 362-365. 
[8] J. Stewart "Cálculo multivariable", México: [10] C. T. Vela, "Estudio sobre el físico-matemático e Thomson, 2004. inventor José Ruiz- Castizo y Ariza (1857-1929)",

[9] E. Swokowsky "Cálculo con geometría analítica", 2a. Tesis doctoral, Universidad de La Rioja, 2013. edición, México: Grupo Editorial Iberoamérica. 